\title{
PLANNED OBSOLESCENCE, CONSUMER PRACTICES AND DESIGN: A SURVEY ON CONSUMER GOODS
}

\author{
Denise Dantas, Dra. (FAU - USP) \\ Lia Assumpção (FAU - USP)
}

The way consumer goods have been produced and sold since the planned obsolescence's implementation is leading society to an environmental limitation in terms of natural resources and an alarming growth in electronic waste generation. Facing such limitation, consumption models and manufacturing are enquired. Electronic waste is a visible consequence of planned obsolescence, but there are others that are invisible, like the practice of buying and discarding products that affects the way we act as a society and consumers. Considering design as an activity intrinsically engaged in social issues, it can be an important tool to modify this scenario.

Planned obsolescence is the name given to the market strategy that encourages repetitive consumption by reducing artifact's lifecycle. In general, this reduction can happen in three ways: a) by the launch of a product in use with a new appearance that makes the previous one outdated (psychological obsolescence); b) by the impossibility of repairing the product in use (artificial obsolescence); c) by its technology no longer working, which slows down some devices or, in some cases, makes its use impossible (technological obsolescence). The aforementioned concepts are based on Packard (1965), Papanek (1971) and Slade (2007) definitions, and supposes the establishment of a date of death of the product at the time of its production, which were inaccessible information that were not part of the objectives of this work. For this reason, it was opted in the research to approach the concept of consumer practices, and through them perceive the existence of planned obsolescence.

The Master's Research, concluded in the middle of 2017, had an exploratory qualitative character and aimed to identify planned obsolescence's manifestations in the Brazilian market, as well as the main products related to it. It also aimed to discuss the relationship between design and the studied phenomenon. The study had three steps: the first consisted of a literature review to define parameters for the identification of types of planned obsolescence. At this stage it was possible to verify the lack of studies related to the subject in Brazil; the second was a questionnaire (with 444 responses collected), preceded by an initial survey, which consisted of creating and monitoring a social networking page - "Made to break". At this stage, it was possible to identify consumption practices and participant's perception towards the studied phenomenon, as well as the most identified products with the types of programmed obsolescence; the third step consisted in five interviews with professionals from the Brazilian industry. The professionals were defined according to the categories most cited in the questionnaire, such as large appliances, cellphones or relevant sectors to the central theme of the research, such as car industry and, thus, it was possible to start a discussion about the relationship between design and planned obsolescence.

The most cited product in the research was the cellphone and its example helps to understand the studied phenomenon. Whether in the past it was an expensive and durable object, today it can be found in variable prices, approaching the concept of disposable in many cases. There are several brands and launches per year. Small improvements in camera's resolution, subtle changes in its design or even the launch of a new color are attractive enough for replacing the device, even if it is still working. On the other hand, impossibility or high cost of devices repairment, and the impossibility of updating a system are also reasons for replacements. Whether in the past, again, the replacements took longer to occur, today they are increasingly constant for the above-mentioned reasons. However, if the exchange of cellphones or other consumer goods may seem common or inevitable today, it was not always like this, and it was not by accident. The encouragement of consumer goods frequent exchange came into force primarily in the United States between the 1920s and 1930s in order to move their economy, then in crisis. The artifact lifecycle was artificially reduced, using what came to be called "planned obsolescence," a term coined by Alfred Sloan, 
General Motors's president in the 1920s, who applied this concepts to the production of cars.

Among the consumer practices researched, durability proved to be of little importance for devices with rapid technological evolution, such as the cell phones. For products without technological characteristics, durability proved to be important, but rare because, according to the research results, there is a great association between cheap and fragile materials, which end up compromising the durability of the products.

In general, it was possible to observe a naturalization of the consumer practices researched, which points to a consequent naturalization of the studied phenomenon. In this way, although the result allows to identify the three types of programmed obsolescence determined by the authors - artificial, psychological and technological -, the research concluded that the concept of planned obsolescence, in the way it was created, is so assimilated today that it ends up making the term itself obsolete. This is because today products do not have to be made to break to be replaced and often discarded.

Figure 1: Electronic devices

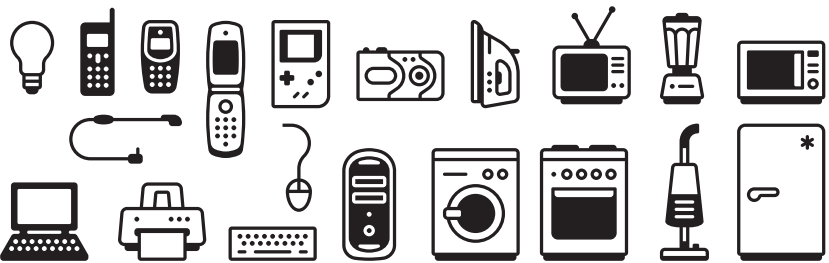

Source: Author

Figure 2: Top selling phones (Iphone 7S Plus and Samsung Galaxy S8)

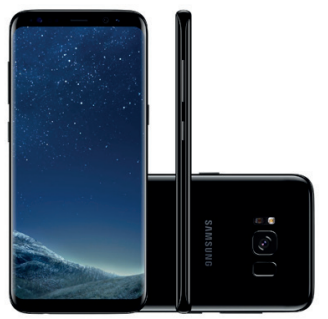

Source: Samsung Galaxy za.com.br/smartphone-samsung-galaxy-s 8-64gb-preto-dual-chip-4g-cam.-12mp-selfie-8mp-tela-5.8-quad-h$\mathrm{d} / \mathrm{p} / 2175625 /$ te/gas8/.) and Apple iphone $7 \mathrm{~S}$ Plus. (http://www. infomoney.com.br/minhas-financas/gadgets/noticia/6000081/ anos-desde-primeiro-iphone-confira-evolucao-smartphone)

\section{Chris Jordan essay:}

Photo essay by Chris Jordan Intolerable Beauty: Portraits of American Mass Consumption 2003 - 2005
Figure 3: Cell phone chargers, Atlanta 2004

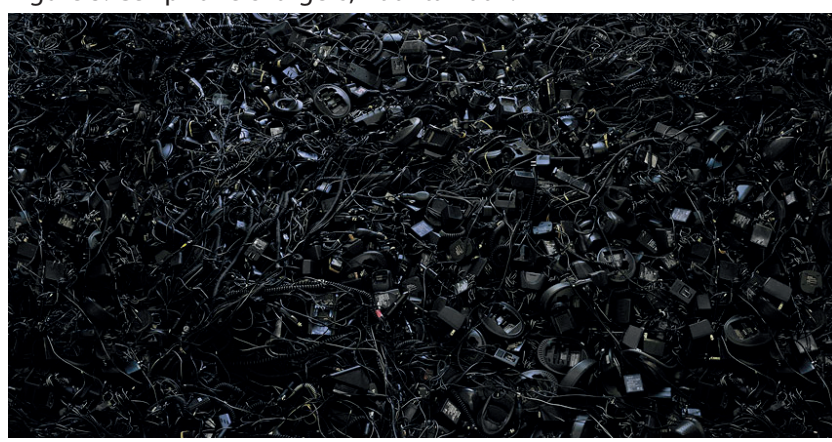

Source: Available in http://www.chrisjordan.com/gallery intolerable/\#cellphone\%20chargers\%2044x66.5

Figure 4: Cell phones, Orlando 2004.

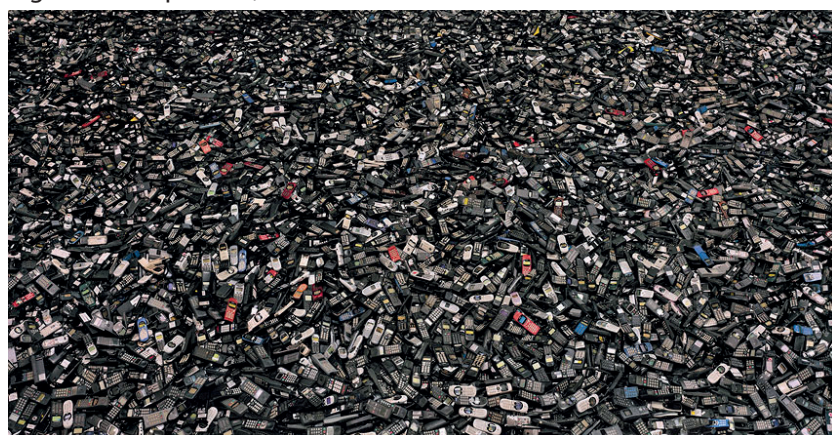

Source: Available in http://www.chrisjordan.com/gallery/ intolerable/\#cellphones\%2044x83)

Figure 5: Crushed Cars, Tacoma 2004

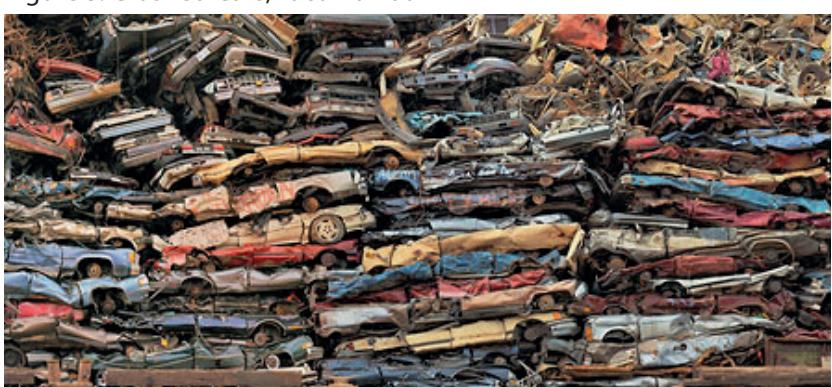

Source: Available in http://www.chrisjordan.com/gallery/ intolerable/\#crushed\%20cars\%201\%2020x83

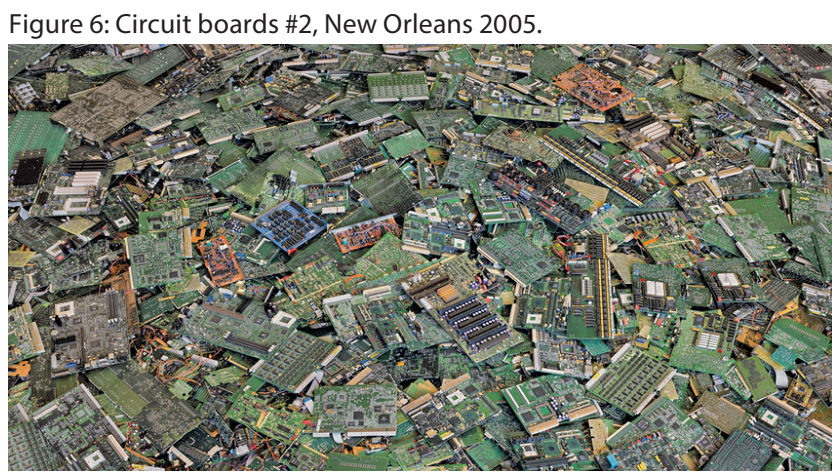

Source: Available in http://www.chrisjordan.com/gallery/ intolerable/\#circuit\%20boards\%202\%2044×60) 
Figure 8: Images that illustrate garbage disposal sites.

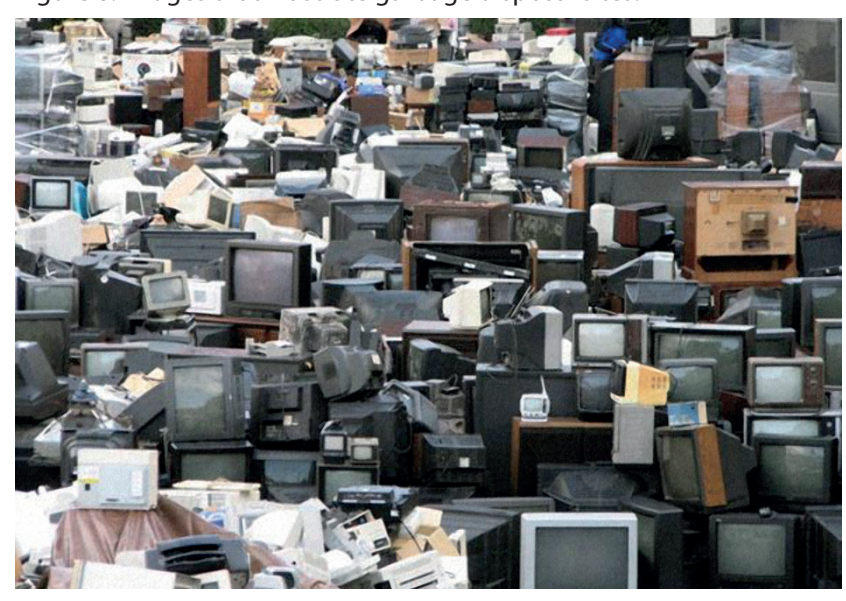

Source: http://www.fragmaq.com.br/blog/entenda-conceito-obsolescencia-programada-impactos-meio-ambiente/) 